\title{
DIVISION XII / COMMISSION 5 / WORKING GROUP ASTRONOMICAL DATA
}

\author{
CHAIR \\ MEMBERS \\ Raymond P. Norris \\ 57
}

\section{TRIENNIAL REPORT 2006 - 2009}

\section{The Working Group}

Astronomers are well aware of the changing nature, volume, and complexity of astronomical data. Most of us are aware that next generation instruments, with Terabyte databases, are going to present enormous challenges to the way that we process data, and our current ways of managing astronomical databases will probably no longer work. So there are a number of initiatives within the astronomical community, most notably the Virtual Observatory, which aim to address these. However, many astronomers are not aware that similar challenges are being met in other disciplines (e.g., geosciences, life sciences, etc.) and that similar solutions are being sought. As a result, astronomy has much to gain from cross-fertilisation with other disciplines.

The Working Group on Astronomical Data (WG-AD) has two key roles: to act as a communication channel between the IAU and CODATA (ICSU Committee on Scientific Data), and to provide a forum for discussion of data issues. Through CODATA, the WGAD also contributes to strategic ICSU activities, such as ICSUs Strategic Committee on Information and Data (SCID), of which the WG-AD chair is a member. SCID has recently released for review a report which proposes, amongst other things, a re-structuring of the World Data Centre system and the Federation for Astronomical and Geophysical data analysis Services (FAGS).

At the 2006 IAU XXVI General Assembly in Prague, 2006, WG-AD held a Special Session on Astronomical Data Management, an important component of which was an electronic discussion in the months leading up to the GA. The WG-AD plans to conduct a similar e-discussion in the months leading up to the 2009 IAU XXVII General Assembly in Rio de Janeiro, Brazil, 2009, focussing particularly on the challenges posed by new instrumentation demands, new ways of managing data, including the Virtual Observatory, and the advent of Petabyte astronomical databases. To ensure that this discussion is relevant and timely, the WG-AD initiated a membership drive to enlist the expertise of those individuals actively engaged in managing next-generation instruments and their data management challenges. As a result of this the membership of the WG-AD has increased in 2008 from 34 to 58. See: See <http://www.atnf.csiro.au/people/rnorris/WGAD/ members.htm>.

\section{CODATA}

CODATA, the ICSU Committee on Data for Science and Technology, is the crossdisciplinary forum in which such issues are addressed. Given the rapidly-changing nature 
of data and its management, it is unsurprising that CODATA is in a process of reinvigoration, and is exploring ways in which it can deliver greater value to science.

The CODATA General Assembly in Beijing, October 2006, included a session on Astronomical Data Management, with talks given by several WG-AD members. In its recentlyreleased Draft Strategic Plan, CODATA identifies three strategic CODATA initiatives, including the Global Information Commons for Science Initiative (GICSI), and identifies a number of ways of achieving greater engagement with the broader scientific community. It also recognises the success of existing CODATA activities such as the Data Science Journal, the Task Groups, and the biennial CODATA conferences, and proposes ways in which these might be made even more effective. CODATA has also adopted a new Mission Statement to reflect these changes.

In conjunction with these new initiatives, CODATA membership is growing. Australia, Ireland, and the UK are in the process of becoming members of CODATA, as has the International Union of Geodesy and Geophysics (IUGG).

Another important development has been the release of the Draft Report of ICSUs Strategic Committee on Information and Data (SCID), whose members included three astronomers. Recommendations of this report include:

- Support for the CODATA Strategic Plan, and a recommendation that CODATA focus on its strategic initiatives.

- A proposed restructuring of the Federation of Astronomical and Geophysical data analysis Services (FAGS) and World Data Center system (WDC) into a new body, the World Data Services (WDS). A measure of success of this new body will be the value that it delivers to bodies such as the existing astronomical data centres and the Virtual Observatory.

- A proposed restructuring of ICSU activities, to enable ICSU to assert a strategic leadership role on behalf of the global scientific community in relation to the policies, management and stewardship of scientific data and information, including the establishment of a new body to work closely with CODATA and WDS.

The next CODATA Conference will take place in Kiev, Ukraine, in October 2008. The conference will include a one-day session on Astronomical Data and the Virtual Observatory and also a meeting of FAGS and WDC representatives to discuss the establishment of the new WDS. Other challenges include the bottleneck in transferring data from journals to data centres. This difficult challenge is being faced by several disciplines, and we have much to learn from each other. Another potential example is that ICSU may be useful in helping these centres achieve their ambitious goals. But it is early days, and we are only just starting to explore potential ways forward.

\author{
Raymond P. Norris \\ chair of the Working Group
}

